This item was submitted to Loughborough's Research Repository by the author.

Items in Figshare are protected by copyright, with all rights reserved, unless otherwise indicated.

\title{
Buckling and vibration of stiffened panels or single plates with clamped ends
}

PLEASE CITE THE PUBLISHED VERSION

PUBLISHER

(C) Multi-Science Publishing Co Ltd

VERSION

VoR (Version of Record)

LICENCE

CC BY-NC-ND 4.0

REPOSITORY RECORD

Watson, Andrew, David Kennedy, F.W. Williams, and Carol A. Featherston. 2009. "Buckling and Vibration of Stiffened Panels or Single Plates with Clamped Ends". figshare. https://hdl.handle.net/2134/5409. 
This item was submitted to Loughborough's Institutional Repository (https://dspace.lboro.ac.uk/) by the author and is made available under the following Creative Commons Licence conditions.

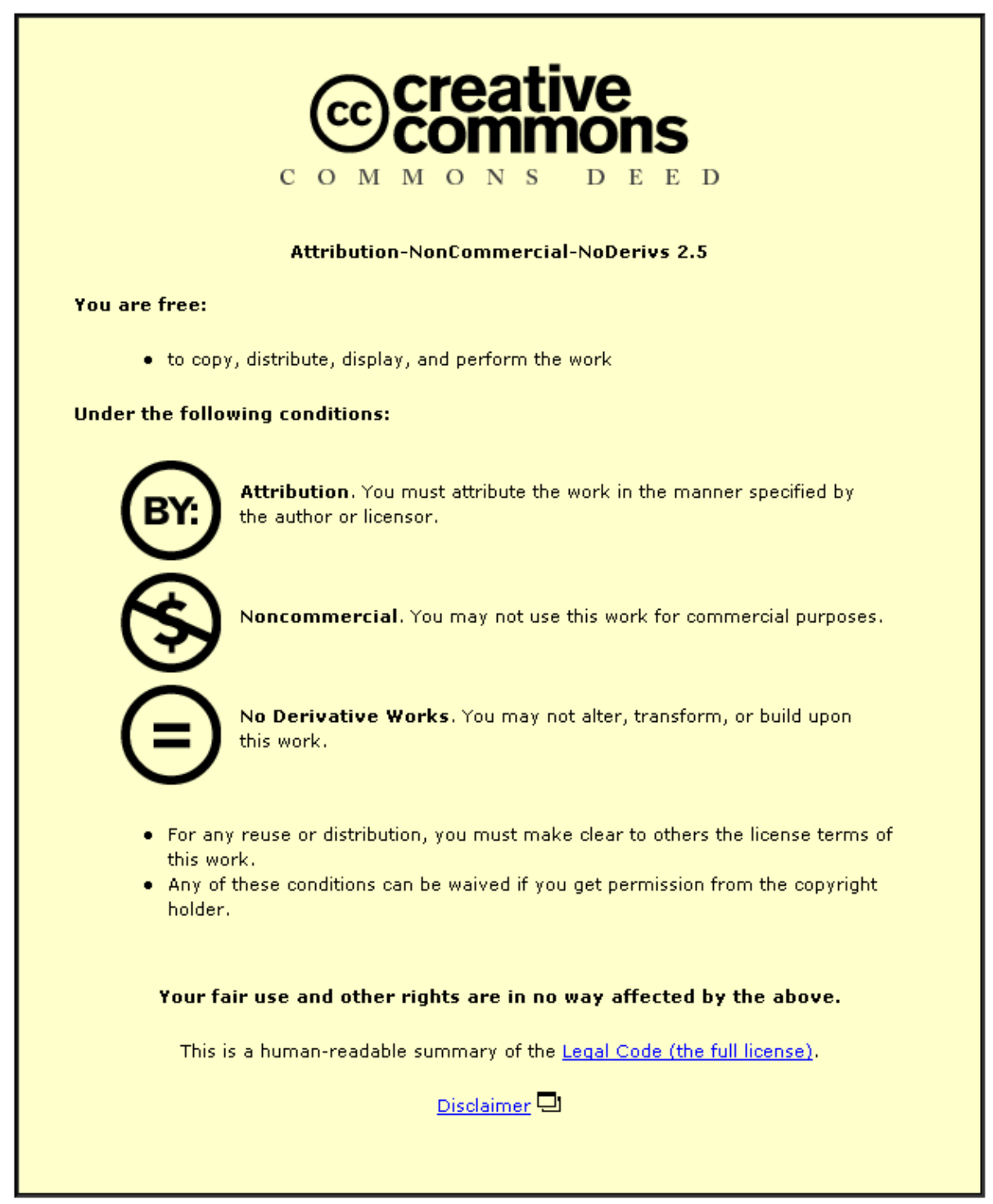

For the full text of this licence, please go to: http://creativecommons.org/licenses/by-nc-nd/2.5/ 


\title{
Buckling and Vibration of Stiffened Panels or Single Plates with Clamped Ends
}

\author{
A. Watson*, D. Kennedy, F. W. Williams and C. A. Featherston \\ Cardiff School of Engineering, Cardiff University, Queen's Buildings, P.O. Box 925, The Parade, Cardiff CF24 0YF, UK \\ (Received 8 April 2002; received in revised form 16 August 2002; accepted 5 September 2002)
}

\begin{abstract}
An efficient method for the buckling and vibration analysis of plates or stiffened panels with clamped ends is presented. The method uses Lagrangian multipliers to couple sinusoidal modes with appropriate half-wavelengths of response, thereby enforcing the end conditions at discrete point supports. Clamped ends can usually be modelled accurately using only a few point supports, while arguments from symmetry often enable some of the required end conditions to be satisfied without explicitly applying constraints. In such cases few half-wavelengths are needed to obtain excellent accuracy. Solutions obtained for the simple limiting case of single plates are exact or within $1 \%$ of the classical or other reported solutions. Solutions obtained for stiffened panels are in close agreement with those obtained using finite element analysis.
\end{abstract}

Key words: Structural analysis, Plate structures, Buckling, Vibration, Clamped ends.

\section{INTRODUCTION}

In aircraft construction the wing panels are typically prismatic plate assemblies, e.g. consisting of a skin with longitudinal stiffeners. The support provided to each panel by the rest of the structure may be regarded as lying between the extreme cases of clamped and simple supports. Analysis of these extreme cases provides upper and lower bounds, respectively, on the critical buckling loads and natural frequencies of the panel. Although much work has been published on the analysis of prismatic plate assemblies, few authors have studied plates and panels with clamped ends, e.g. see Mead et al., (1988); Ingber et al., (1992); Young (1989); Yuan and Dickinson (1995); Liew et al., (1990); Wang et al., (1994). Other related work, e.g. Liew and Lam (1990); Wang et al., (1993); Liew and Wang (1992, 1995), covers skew plates, polygonal plates, plates with free edges and plates with internal supports; these extensions are not considered in the present paper.

The widely used computer program VICONOPT of
Butler and Williams (1992) is the analysis tool used to obtain the results presented in this paper for single plates and stiffened panels with clamped ends. For single plates comparisons are made with classical and other reported results. In the case of stiffened panels no such results were found in the literature, so comparisons were made using the finite element package ABAQUS, see Hibbitt et al., (1997), as in Lillico et al., (2000).

VICONOPT is a computer program which incorporates the earlier programs VIPASA, see Wittrick and Williams (1974), and VICON, see Anderson et al., (1983). VICONOPT uses a transcendental stiffness matrix approach based on exact solutions to the governing differential equations and covers any prismatic assembly of isotropic, orthotropic or anisotropic plates, each of which can carry any combination of longitudinally invariant in-plane longitudinal, transverse and shear stresses. It can be used as either an analysis or an optimum design program. Its VIPASA and VICON analysis options are both used to calculate the eigenvalues, i.e. the critical

*Corresponding author. Email watsona1@cardiff.ac.uk; Fax and Tel: +44 (0) 2920874826. 
load factors in buckling problems or the natural frequencies in undamped vibration problems. The VICON option is used for overall modes and the VIPASA option for shorter wavelength modes. The VICON option can be used to solve any analysis problem which could otherwise be solved by VIPASA, but has substantial additional capability because it models end conditions much more accurately for overall modes of plate assemblies with substantial in-plane shear loads, for which VIPASA gives very conservative results. This is because VIPASA assumes that the modes of buckling or vibration have a sinusoidal longitudinal variation with half-wavelength $\lambda$, whereas VICON modes are sums of such VIPASA modes obtained by coupling different values of $\lambda$, as is described in Section 2.

This paper describes extensions to the VICON option to permit the modelling of clamped end conditions. Most of the results presented were obtained using these extensions, while some comparative checks were made using the VIPASA option.

\section{NECESSARY INFORMATION ABOUT VICONOPT}

The VICON option of VICONOPT assumes an infinitely long plate assembly and uses Lagrangian multipliers to couple the responses for an appropriate set of half-wavelengths $\lambda_{\mathrm{m}}$, so as to satisfy point support conditions at the ends, edges or interior of the panel which repeat at intervals of $l$ in the longitudinal (x) direction of Figure 1. Thus a plate assembly of finite length $l$ with simply supported ends may be modelled reasonably accurately if the simple support along the transverse line at $\mathrm{x}=0$ is represented by enforcing $\mathrm{w}=0$ at a sufficient number of point supports at $x=0$, denoted by crosses in Figure 1, thus also implying identical supports at $\mathrm{x}=l$. Note that point supports can only be introduced at longitudinal junctions (i.e. nodes) between the plates of an assembly, so that it is necessary to introduce such line junctions wherever there are point supports, as indicated by the dashed lines on Figure 1.
The results assume that the mode repeats over a length $\mathrm{L}=2 l / \xi$ for some value $0 \leq \xi \leq 1$. Each value of $\xi$ generates an infinite series of $\lambda_{\mathrm{m}}$, given by

$$
\lambda_{\mathrm{m}}=l /(\xi+2 \mathrm{~m}) \quad(\mathrm{m}=0, \pm 1 \pm, 2, \pm 3, \pm 4, \ldots)
$$

so that $\xi=0$ modes are identical in adjacent longitudinal bays whereas $\xi=1$ modes are reversed. In practice the series is truncated by choosing a value of q such that acceptable results are obtained by considering only the $\lambda_{\mathrm{m}}$ for which, in Eqn $1,0 \leq \mathrm{m}<\mathrm{q}$ if $\xi=0$ or $\xi=1$, and $-\mathrm{q} \leq \mathrm{m} \leq \mathrm{q}$ if $0<\xi<1$. Negative values of $\lambda_{\mathrm{m}}$ denote the use of complex conjugate stiffness matrices in order to reverse the direction of the response, see Anderson et al., (1983). Table 1 lists the values of $\lambda_{\mathrm{m}}$ derived from Eqn 1 for typical values of $\xi$, it being noted that the analysis for negative values of $\mathrm{m}$ is omitted for $\xi=0$ and $\xi=1$ because the response for any negative halfwavelength $\lambda_{\mathrm{m}}$ can be deduced from that for halfwavelength $\lambda_{\mathrm{m}}$.

Fully converged results are obtained by increasing

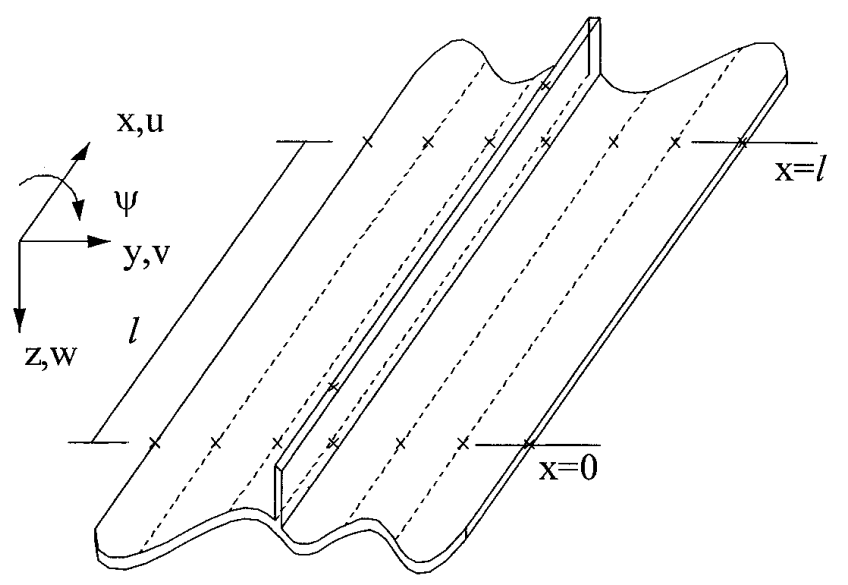

Figure 1. Sketch representing an infinitely long plate assembly with a single blade stiffener and free longitudinal edges, showing the axis system $(\mathrm{x}, \mathrm{y}, \mathrm{z})$ and the displacement system $(\mathrm{u}, \mathrm{v}, \mathrm{w}, \psi)$. Crosses denote the positions of the point supports used to model the end conditions.

\section{Table 1. Half-wavelengths $\lambda \mathrm{m}$ used in VICON type analysis of a plate assembly of length / with $q=3$ ( $\lambda m=\infty$ denotes rigid body displacements)}

\begin{tabular}{cll}
$\xi$ & $\lambda \mathrm{m}$ \\
\hline 0 & $\infty, l / 2, l / 4$. \\
0.25 & $4 l,-4 l / 7,4 l / 9,-4 l / 15,4 l / 17,-4 l / 23,4 l / 25$. \\
0.5 & $2 l,-2 l / 3,2 l / 5,-2 l / 7,2 l / 9,-2 l / 11,2 l / 13$. \\
0.75 & $4 l / 3,-4 l / 5,4 l / 11,-4 l / 13,4 l / 19,-4 l / 21,4 l / 27$. \\
1 & $l, l / 3, l / 5$.
\end{tabular}


both $\mathrm{q}$ and $\mathrm{n}$, the number of point supports (which may be assumed to be equally spaced). Convergence on the critical buckling load factors or natural frequencies is from above as $\mathrm{q}$ is increased and from below as $\mathrm{n}$, the number of point supports, is increased.

Eqn 2 below shows the Hermitian overall stiffness and constraint matrix $\mathbf{K}$ used by the VICON option of VICONOPT, see Anderson et al., (1983). Only the populated locations contain all the non-zero elements and the superscript $\mathrm{H}$ denotes Hermitian transpose. The matrices $\mathbf{K}_{\mathrm{m}}$ are stiffness matrices corresponding to half-wavelengths $\lambda_{\mathrm{m}}$. The matrices $\mathbf{e}_{\mathrm{m}}$ are approximately triangular and contain the constraints which couple the different values of $\lambda_{\mathrm{m}}$. Their Hermitian transposes $\mathbf{e}_{\mathrm{m}}{ }^{\mathrm{H}}$ contain coefficients of the Lagrangian multipliers which enforce the constraints.

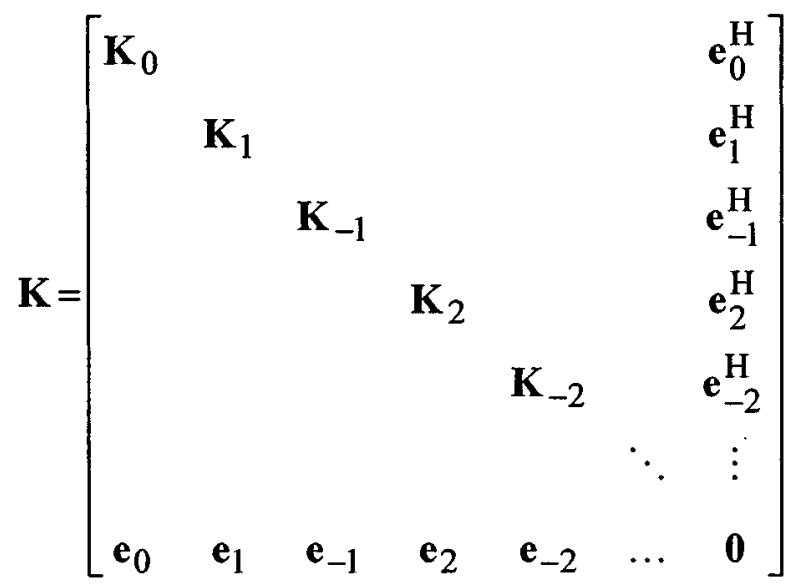

The number of eigenvalues exceeded by any trial value of load factor or frequency is given by

$$
\mathbf{J}=\sum_{\mathrm{m}}\left(\mathrm{J}_{0 \mathrm{~m}}+\mathrm{s}\left\{\mathbf{K}_{\mathrm{m}}\right\}\right)+\mathrm{s}\{\mathbf{R}\}-\mathbf{r}
$$

where $\mathrm{J}_{0 \mathrm{~m}}$ is the number of eigenvalues which would be exceeded for half-wavelength $\lambda_{\mathrm{m}}$ if all of the degrees of freedom at the longitudinal junctions between the plates of the assembly were to be clamped and $\mathrm{s}\{\}$ is the sign count of a matrix, i.e. the number of negative elements on its leading diagonal after it has been reduced to upper triangular form by the usual form of Gauss elimination, in which multiples of the pivotal row are added to (unscaled) succeeding rows. $\mathrm{r}$ is the number of constraints and so is also the order of the matrix $\mathbf{R}$, which replaces the shaded null matrix of Eqn 2 when Gauss elimination is applied to the overall matrix of Eqn 2 and is arrested after all rows in the stiffness matrices $\mathbf{K}_{\mathrm{m}}$ have been pivotal. Convergence on the critical buckling load factors or natural frequencies is achieved by calculating $\mathrm{J}$ at appropriately chosen successive trial values of the load factor or frequency.

\section{MODELLING A CLAMPED END CONSTRAINT}

The displacement vector $\mathbf{D}_{\mathrm{A}}$, at any longitudinal location $\mathrm{x}$ of the plate assembly shown in Figure 1, is given by

$$
\mathbf{D}_{\mathrm{A}}=\sum_{\mathrm{m}} \mathbf{D}_{\mathrm{m}} \exp \left(\mathrm{i} \pi \mathrm{x} / \lambda_{\mathrm{m}}\right)
$$

where $\mathrm{i}=\sqrt{-}-1$ and $\mathbf{D}_{\mathrm{m}}$ is the complex displacement amplitude vector comprising the amplitudes of $\mathrm{u}, \mathrm{v}, \mathrm{w}$ and $\psi$ responses associated with half-wavelength $\lambda_{m}$.

\subsection{Approximate Model}

Referring to Figure 1, a clamped end support could previously be modelled approximately by VICONOPT by requiring that $u$ be zero at the nodes at the top and bottom edges of the stiffener, that the out-of-plane skin displacement $\mathrm{w}$ be zero at $\mathrm{x}=0$ and at $\mathrm{x}=\boldsymbol{\varepsilon}$ for all skin nodes, where $\varepsilon$ is some small positive distance, and that the out-of-plane $\mathrm{v}$ displacement be zero at the node at the top edge of the stiffener at $\mathrm{x}=0$ and $\mathrm{x}=\varepsilon$. These requirements for $\mathrm{w}$ and $\mathrm{v}$ give constraints of the form

$$
\begin{gathered}
\sum_{m} D_{m j}=0 \\
\sum_{m} D_{m j} \exp \left(i \pi \varepsilon / \lambda_{m}\right)=0
\end{gathered}
$$

where $\mathrm{D}_{\mathrm{mj}}$ is the jth element of $\mathbf{D}_{\mathrm{m}}$ and represents the $\mathrm{w}$ (or v) displacement at one of the constrained nodes. (In the following only $\mathrm{w}$ is considered explicitly because the extension to $\mathrm{v}$ is obvious. Also the $\mathrm{u}=0$ constraints are not affected by the analysis of this paper.) Expanding Eqn 6 as a Taylor series in $\varepsilon$ gives

$$
\sum_{\mathbf{m}} \mathrm{D}_{\mathrm{mj}}\left[1+\left(\mathrm{i} \pi \varepsilon / \lambda_{\mathrm{m}}\right)+\mathrm{O}\left(\varepsilon^{2}\right)\right]=0 .
$$

Subtracting Eqn 5 from Eqn 7 gives

$$
\sum_{m} D_{m j}\left[i \pi \varepsilon / \lambda_{m}+O\left(\varepsilon^{2}\right)\right]=0
$$

or, substituting from Eqn 1 and taking the limit as $\varepsilon \rightarrow 0$,

$$
\sum_{\mathrm{m}} \mathrm{D}_{\mathrm{mj}}[\mathrm{i} \pi(\xi+2 \mathrm{~m}) / l]=0
$$

\subsection{Exact Model}

The present extensions to VICONOPT permit 
modelling of the clamped end support more precisely by requiring that both $\mathrm{w}=0$ and $\partial \mathrm{w} / \partial \mathrm{x}=0$ at $\mathrm{x}=0$, so that Eqn 6 is replaced by

$$
\sum_{m} D_{m j}\left(i \pi / \lambda_{m}\right)=0
$$

which, on substitution from Eqn 1, becomes Eqn 9 showing the equivalence of this exact model and the limiting case of the approximate model of Section 3.1.

\subsection{Arguments from Symmetry Applied to Clamped Ends}

Consider the infinitely long prismatic plate assembly shown in Figure 2, whose geometry, loading and support conditions are all assumed to be symmetric about $x=l / 2$. The plate assembly geometry satisfies this symmetry requirement because it is prismatic, provided every plate is isotropic or orthotropic. The loading shown also satisfies the symmetry requirement because there is no shear load. Only point supports are considered here so, in order to ensure symmetry of the support conditions about $\mathrm{x}=l / 2$, any support at the point $(\mathrm{x}, \mathrm{y})(0 \leq \mathrm{x}<l,-\mathrm{B} / 2 \leq \mathrm{y} \leq \mathrm{B} / 2)$ must be paired with one at the point $(l-\mathrm{x}, \mathrm{y})$. Consider now the $\mathrm{w}$ displacements $\mathrm{w}_{\mathrm{P}}$, $\mathrm{w}_{\mathrm{Q}}$ and $\mathrm{w}_{\mathrm{Q}}$, at the symmetrically placed points $\mathrm{P}\left(\mathrm{x}_{\mathrm{P}}, \mathrm{y}_{\mathrm{P}}\right)$ and Q $\left(l-\mathrm{x}_{\mathrm{P}}, \mathrm{y}_{\mathrm{P}}\right)$ shown in Figure 2, and at Q' $\left(-\mathrm{x}_{\mathrm{P}}, \mathrm{y}_{\mathrm{P}}\right)$ which is the counterpart to $\mathrm{Q}$ in the previous longitudinal bay, respectively. Because of the symmetry of the structure and its loading and supports, the modes of buckling or vibration must be either symmetric (S) or anti-symmetric (A) about $x=l / 2$. Consider first the symmetric cases.

\subsection{Modes Symmetric about $x=I / 2$ (S Cases)}

Because of the symmetry $\mathrm{w}_{\mathrm{Q}}=\mathrm{w}_{\mathrm{P}}$ for all positions of $\mathrm{P}$ $\left(0 \leq \mathrm{x}_{\mathrm{P}}<l,-\mathrm{B} / 2 \leq \mathrm{y}_{\mathrm{P}} \leq \mathrm{B} / 2\right)$. For $\xi=0$, Eqns 1 and 4 show that the mode shape is identical in every longitudinal bay. Thus letting $x_{P} \rightarrow 0$ gives $\partial w / \partial x=0$ at $x=0$ for all $y$ because $\mathrm{w}_{\mathrm{Q}}=\mathrm{w}_{\mathrm{Q}}=\mathrm{w}_{\mathrm{P}}$ and $\mathrm{Q}^{\prime}$ and $\mathrm{P}$ are infinitesimally separated. Hence enforcing $S$ modes to have $\xi=0$ automatically satisfies the requirement $\partial \mathrm{w} / \partial \mathrm{x}=0$ along the whole of the transverse line at $x=0$ even if the plate assembly is completely unsupported. (In practice one point support is needed at $\mathrm{x}=0$ to ensure that the mode starts at $\mathrm{x}=0$, otherwise the axis of symmetry could move away from $\mathrm{x}=l / 2$.)

For $\xi=1$, the mode shape is reversed in successive longitudinal bays. Thus letting $\mathrm{x}_{\mathrm{P}} \rightarrow 0$ gives $-\mathrm{w}_{\mathrm{Q}}=\mathrm{w}_{\mathrm{Q}}=\mathrm{w}_{\mathrm{P}}$ so that as $\mathrm{x}_{\mathrm{P}} \rightarrow 0$, the requirement $\mathrm{w}=0$ is automatically satisfied along $\mathrm{x}=0$.

Figure 3(a) shows examples of S modes for (i) $\xi=0$ and (ii) $\xi=1$, in which, respectively, the requirements $\partial w / \partial x=0$ and $w=0$ are automatically satisfied at $x=0$ and $\mathrm{x}=l$ for the responses corresponding to two of the halfwavelengths $\lambda_{\mathrm{m}}$ listed in Table 1 . The remaining requirement, i.e. $\mathrm{w}=0$ for $\xi=0$ and $\partial \mathrm{w} / \partial \mathrm{x}=0$ for $\xi=1$, is satisfied by adding point supports along the transverse line $x=0$, so that the responses are combined to give a mode which is symmetric about $\mathrm{x}=l / 2$ and satisfies the clamped end conditions $w=0$ and $\partial w / \partial x=0$ at both $x=0$ and $\mathrm{x}=l$.

\subsection{Modes Anti-symmetric about $x=I / 2(A$ Cases)}

For anti-symmetric (A) cases $\mathrm{w}_{\mathrm{Q}}=-\mathrm{w}_{\mathrm{P}}$. By reasoning analogous to that of Section 3.4, it is seen from Figure

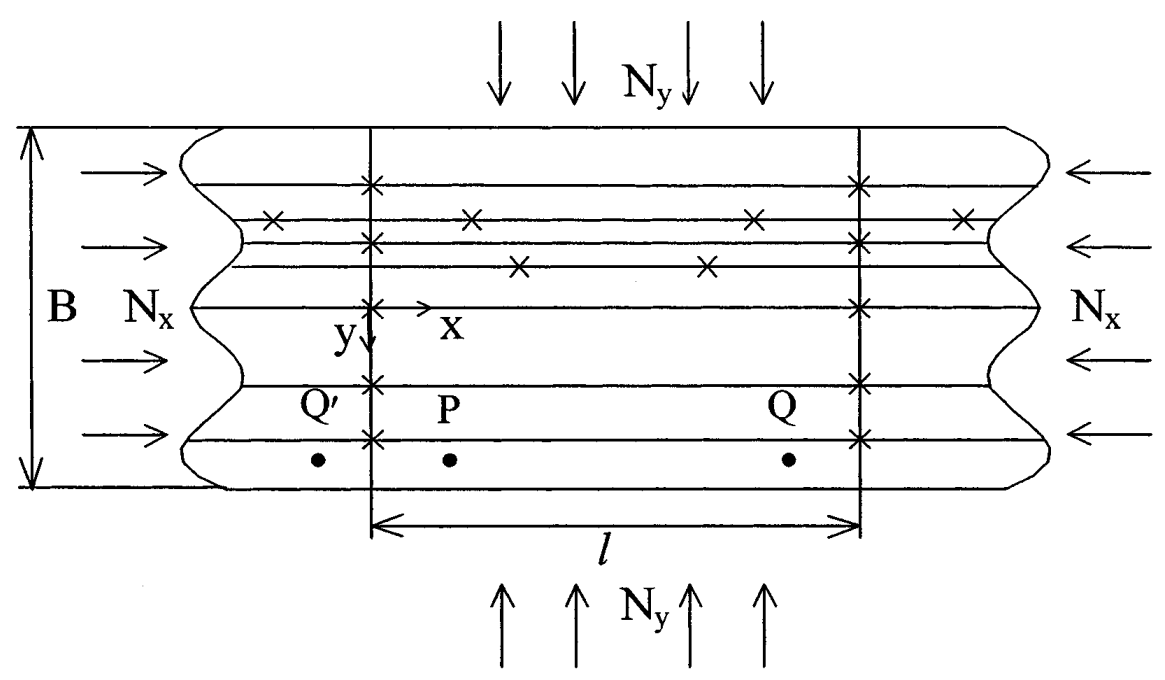

Figure 2. Plan view of a representative prismatic plate assembly which is symmetric about $x=l / 2$ and is loaded by longitudinally invariant longitudinal $\left(\mathrm{N}_{\mathrm{x}}\right)$ and transverse $\left(\mathrm{N}_{\mathrm{y}}\right)$ compressive loads per unit width. Crosses denote point supports, dashed lines are the line junctions they require, and the two solid longitudinal lines are plan views of blade stiffeners. 
2 that for $\xi=0, \mathrm{w}_{\mathrm{Q}}=\mathrm{w}_{\mathrm{Q}}=-\mathrm{w}_{\mathrm{P}}$ so that $\mathrm{w}=0$ is automatically satisfied along $\mathrm{x}=0$. Similarly for $\xi=1$, $\mathrm{w}_{\mathrm{Q}}=-\mathrm{w}_{\mathrm{Q}}=\mathrm{w}_{\mathrm{P}}$ so that $\partial \mathrm{w} / \partial \mathrm{x}=0$ is automatically satisfied along $\mathrm{x}=0$.

Figure 3(b) shows examples of A modes for (i) $\xi=0$ and (ii) $\xi=1$, in which these requirements are automatically satisfied by responses corresponding to two half-wavelengths $\lambda_{\mathrm{m}}$. These responses are combined, using suitable point supports at $x=0$, to give a mode which is anti-symmetric about $\mathrm{x}=l / 2$ and satisfies the clamped end conditions.

\subsection{Selection of Point Constraints}

In order to model clamped ends, it is required to constrain both $\mathrm{w}$ and $\partial \mathrm{w} / \partial \mathrm{x}$ (or $\mathrm{v}$ and $\partial \mathrm{v} / \partial \mathrm{x}$ for the free edge of the stiffener) to be zero at the lines of supports shown in Figure 1, i.e. at $\mathrm{x}=0$ (and therefore by implication at $\mathrm{x}=l$ ). To consider all $\xi$ values in a single run, sufficient constraints must be introduced at $\mathrm{x}=0$ so that both $w$ and $\partial w / \partial x$ are set to zero at suitably chosen points. For a stiffened panel, it is assumed that sufficient $\mathrm{u}=0$ constraints are also imposed to prevent rotation and/or shearing of the stiffeners.

However if only symmetric modes are required some of these constraints can be omitted, as follows. For $\xi=0$, symmetric modes can be obtained by omitting the $\partial \mathrm{w} / \partial \mathrm{x}=0($ or $\partial \mathrm{v} / \partial \mathrm{x}=0)$ constraints, because Section 3.4 shows that such constraints are automatically satisfied.
Similarly, for $\xi=1$ symmetric modes can be obtained by omitting the $\mathrm{w}=0$ (or $\mathrm{v}=0$ ) constraints. Conversely, if only anti-symmetric modes are required they can be obtained for $\xi=0$ by omitting the $\mathrm{w}=0$ (or $\mathrm{v}=0$ ) constraints and for $\xi=1$ by omitting the $\partial \mathrm{w} / \partial \mathrm{x}=0$ (or $\partial \mathrm{v} / \partial \mathrm{x}=0$ ) constraints.

It should be noted that, although these procedures of omitting constraints are certain to find all the clamped end modes for $\xi=0$ and $\xi=1$, other modes may also be found which do not satisfy the clamped end requirements. Thus results should be checked carefully and it may be necessary (even in buckling analysis) to consider eigenvalues higher than the first for each value of $\xi$.

\subsection{Physical Arguments for Choice of $\xi$}

For a panel symmetric about $\mathrm{x}=l / 2$ with clamped ends at $\mathrm{x}=0$ and $\mathrm{x}=l$, all modes must be either $\mathrm{S}$ or $\mathrm{A}$. $\xi$ determines the number of longitudinal bays over which the modes repeat and q, defined below Eqn 1, needs to be high enough to give an accurate representation of the clamped mode in every bay. All the displacement amplitudes are multiplied by $\exp (\mathrm{i} \pi \mathrm{x} / \lambda \mathrm{m})$, see Eqn 4 . The theory therefore allows for the possibility of sine waves or cosine waves or combinations of sine and cosine waves, for each of the half-wavelengths $\lambda \mathrm{m}$ in the series listed in Table 1.

For $\xi=0$, the cosine waves of Table 1 are very suitable

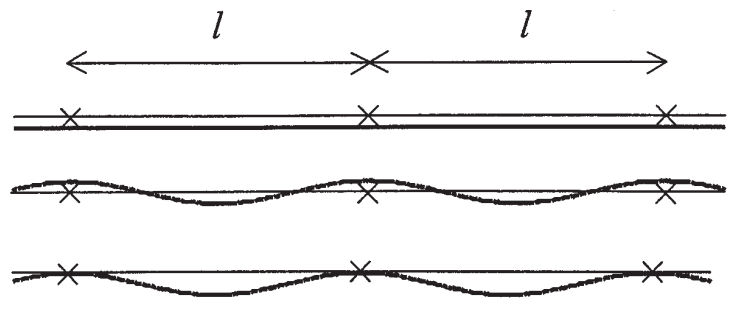

(i)

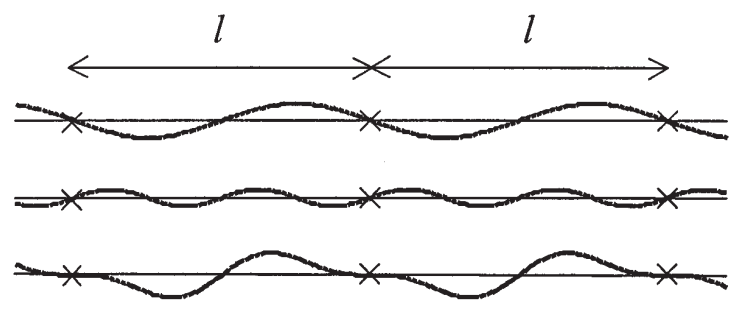

(i)

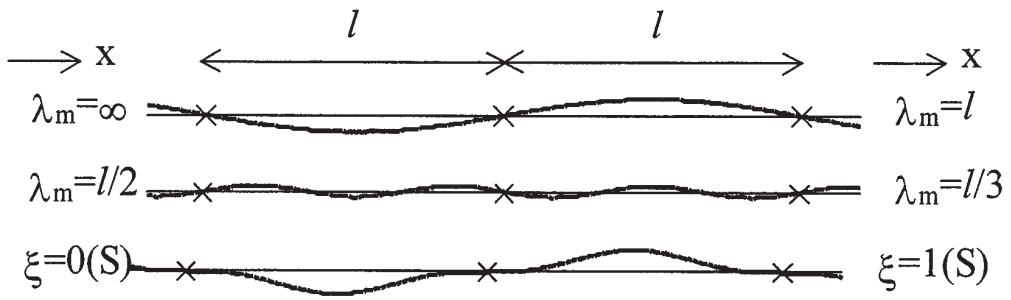

(ii)

(a)

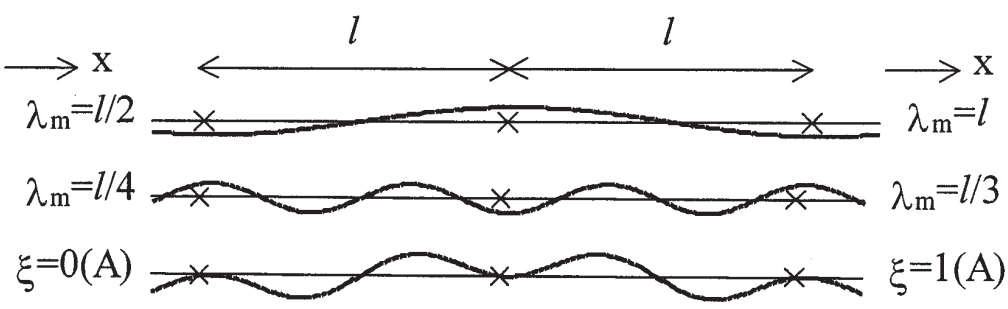

(ii)

(b)

Figure 3. Examples of (a) symmetric (S) modes and (b) anti-symmetric (A) modes for any infinitely long stiffened panel, showing out-ofplane skin displacements plotted over two longitudinal bays of length $l$. Each case shows, for both (i) $\xi=0$ and (ii) $\xi=1$, sinusoidal responses associated with only two half-wavelengths $\lambda_{\mathrm{m}}$ and their combination into a mode satisfying clamped end conditions at longitudinal intervals of $l$, i.e. at the locations marked by crosses. 
for finding $\mathrm{S}$ modes because all terms in the series automatically meet the requirement $\partial \mathrm{w} / \partial \mathrm{x}=0$ at $\mathrm{x}=0$ and also satisfy the symmetry requirement $\partial \mathrm{w} / \partial \mathrm{x}=0$ at $\mathrm{x}=$ $l / 2$. The cosine wave series can never find A modes because A modes generally have a non-zero slope $\partial w / \partial x$ at $x=l / 2$. The sine wave series gives zero displacement at $\mathrm{x}=0, \mathrm{x}=l / 2$ and $\mathrm{x}=l$ and so can find the A modes; however convergence tends to be slow, i.e. a high value of $\mathrm{q}$ is required. (This can be demonstrated by Fourier analysis.)

Arguments similar to those of the previous paragraph show that the cosine waves of Table 1 for $\xi=1$ all have $\partial \mathrm{w} / \partial \mathrm{x}=0$ at the ends and $\mathrm{w}=0$ at $\mathrm{x}=l / 2$, which are both requirements of A modes. (The cosine waves are $\mathrm{A}$ and the sine waves are S.) Therefore the A modes are given by very small values of $\mathrm{q}$ and cosine waves alone for $\xi=1$, the cosine waves being combined in an appropriate way to give $\mathrm{w}=0$ at $\mathrm{x}=0$, see Figure 3 .

Physical arguments imply that all clamped end modes can be obtained from both $\xi=0$ and $\xi=1$. For a given number of point supports, the results are slightly different because, for the $\xi=0$ mode, one of the conditions $w=0$ and $\partial w / \partial x=0($ or $v=0$ and $\partial v / \partial x=0)$ is satisfied all along $\mathrm{x}=0$ and the other condition is satisfied only at the point supports, and vice-versa for the $\xi=1$ mode. However as the number of point supports is increased, the fully converged results for $\xi=0$ and $\xi=1$ are identical. Other values of $\xi$ (i.e. $0<\xi<1$ ) give the same results, usually with poor convergence.

An efficient solution procedure is to find $\mathrm{S}$ modes by solving for $\xi=0$ and applying $\mathrm{w}=0$ constraints at each node, and to find A modes by solving for $\xi=1$ and applying $\mathrm{w}=0$ constraints at each node. In each case, the addition of a $\partial w / \partial x=0$ constraint at only one of the nodes at $x=0$ ensures satisfaction of the clamped end requirements. A simple alternative procedure, which gives adequate accuracy, is to apply $w=0$ and $\partial w / \partial x=0$ (or $\mathrm{v}=0$ and $\partial \mathrm{v} / \partial \mathrm{x}=0$ ) constraints at each node, solving for both $\xi=0$ and $\xi=1$ and taking the lower of the two results obtained.

\subsection{Finite Element Analysis}

A comparative analysis was carried out using the commercial finite element code ABAQUS, see Hibbit et al., (1997). For this analysis the panel mesh was constructed using eight noded thin shell elements with edge behaviour modelled using quadratic equations which satisfied Kirchoff's constraint numerically. These elements provide for arbitrarily large rotations but small strains. The change in thickness with deformation is ignored with these elements. The elements therefore behaved in a manner consistent with thin shell theory. Stresses, strains and displacements were calculated at four integration points and then extrapolated to give the values at each node. The nodes had five degrees of freedom, three displacements and two in-plane rotations.

The boundary conditions were selected to represent, as closely as possible, those of the VICONOPT model. In order to model a panel subject to axial compression, at one end all five degrees of freedom were constrained to represent a clamped condition, whilst at the other end, to which the compressive load was applied, displacement was allowed in the direction of load application, all other freedoms being restrained. The two simply supported edges were modelled by preventing out of plane displacement and axial rotation. These boundary conditions were modified slightly for the case of a panel under shear where in addition to these constraints, axial displacement was prevented along the simply supported edges so as to allow the development of complementary shear forces.

\section{Table 2. Example problems}

\begin{tabular}{cccccc} 
Example & Type & Edge support $\dagger$ & End support $\dagger$ & Loadingt & Results in Table \\
\hline 1 & plate & $\mathrm{S}$ & $\mathrm{C}$ & $\mathrm{N}_{\mathrm{x}}$ & 3 \\
$1^{*}$ & plate & $\mathrm{C}$ & $\mathrm{S}$ & $\mathrm{N}_{\mathrm{y}}$ & 3 \\
2 & plate & $\mathrm{C}$ & $\mathrm{C}$ & $\mathrm{N}_{\mathrm{x}}$ & 4 \\
3 & plate & $\mathrm{C}$ & $\mathrm{C}$ & $\mathrm{N}_{\mathrm{xy}}$ & 5 \\
4 & plate & $\mathrm{S}$ & $\mathrm{C}$ & vibration & 6 \\
$4^{*}$ & plate & $\mathrm{C}$ & $\mathrm{S}$ & vibration & 6 \\
5 & plate & $\mathrm{C}$ & $\mathrm{C}$ & vibration & 7 \\
6 & panel & $\mathrm{C}$ & $\mathrm{C}$ & $\mathrm{N}_{\mathrm{x}}$ & 8 \\
7 & panel & $\mathrm{C}$ & $\mathrm{C}$ & $\mathrm{N}_{\mathrm{xy}}$ & \\
\hline
\end{tabular}

$\uparrow \mathrm{S}$ - simple support; $\mathrm{C}$ - clamped

$+\mathrm{N}_{\mathrm{x}}-$ longitudinal; $\mathrm{N}_{\mathrm{y}}-$ transverse; $\mathrm{N}_{\mathrm{xy}}-$ shear 
In both cases, load was applied to one non-structural node, located in the centre of one end of the panel. Each node at that end was then constrained such that its displacement in the direction of loading was identical to that of the non-structural node, thus creating the effect of a rigid support.

\section{RESULTS}

Table 2 lists the example problems considered. The results for examples 1-5 are for isotropic plates and are given in Tables 3-7 in terms of the non-dimensional buckling parameter

$$
k=\left(1-v^{2}\right)\left(\sigma^{\prime} / E\right)(b / t)^{2}
$$

and the non-dimensional frequency parameter

$$
f=\left(\omega^{\prime} l^{2} / t\right) \sqrt{ }\left[12\left(1-v^{2}\right) \rho / E\right]
$$

where $\sigma^{\prime}$ is the critical buckling stress, $\omega^{\prime}$ is the radian natural frequency, $\mathrm{E}$ is the modulus of elasticity, ( is Poisson's ratio, $v$ is the density, $\rho$ is the breadth of the plate, $\mathrm{t}$ is its thickness and $l$ is its length.

The VICON results were obtained by first finding $\mathrm{k}$ (or $\mathrm{f}$ ) for various values of $\mathrm{q}$ and $\mathrm{n}$. $\mathrm{k}$ (or $\mathrm{f}$ ) was plotted against $1 / q^{2}$ for a particular value of $n$ and a converged result was obtained by extrapolation to the $\mathrm{k}$ (or $\mathrm{f}$ ) axis. Then $\mathrm{n}$ was increased until there was a negligible difference in the converged values of $k$ (or $f$ ). This procedure is illustrated in Figure 4(a) for the first case of Table 2 with $l / b=1.0$ which illustrates that there is negligible difference when varying $\mathrm{n}$ for $\xi=0$; and Figure 4(b) which illustrates that there is convergence on essentially the same result for all values of $\xi(0 \leq \xi \leq 1)$. $\xi=0$ gives the most rapid convergence due to the mode being of S type.

The results of Tables 3-7 agree well with the results of other authors, see Mead et al., (1988); Yuan and Dickinson (1995); Timoshenko and Gere (1961); Leissa (1969); Liew et al., (1990). Tables 3 and 6 also show good agreement between the results for examples 1 and 4 and those for examples $1^{*}$ and $4^{*}$, respectively, which were obtained by rotating the plate, and the loading (for example 1), by $90^{\circ}$ and using VIPASA analysis, so that simply supported ends were assumed and clamped edges

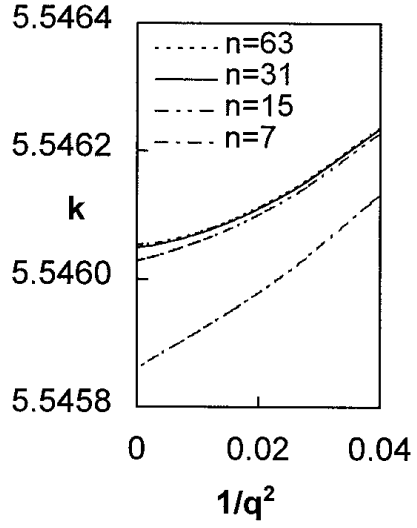

(a)

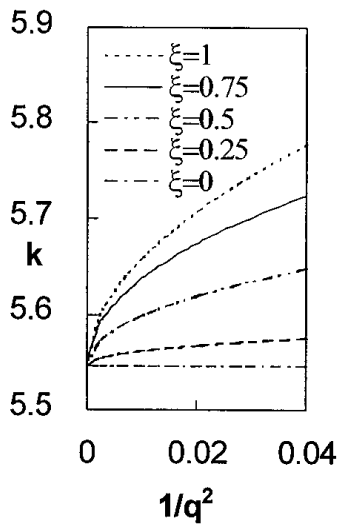

(b)
Figure 4. Plot of K versus 1/q2 for panel of example 1 with aspect ratio $l / b=1.0$ (a) Extrapolation used to obtain results shown in Table 3 ( $\xi=0$ ); (b) Convergence for different values of $\xi$ with $\mathrm{n}=63$. The curves were plotted through points given by $5 \leq \mathrm{q} \leq 80$.

Table 3. Values of the non-dimensional buckling parameter $k$ obtained for longitudinally loaded isotropic rectangular plates, simply supported along

\begin{tabular}{|c|c|c|c|c|c|c|}
\hline $\begin{array}{c}\text { Aspect ratio } \\
l / \mathrm{b}\end{array}$ & $\begin{array}{c}\text { VICON } \\
\text { Example } 1\end{array}$ & $\begin{array}{c}\text { VIPASA } \\
\text { Example } 1 *\end{array}$ & $\begin{array}{c}\text { Timoshenko } \\
\text { and Gere (1961) }\end{array}$ & Mode & $\xi$ & $\begin{array}{c}\mathrm{k} \\
\text { (approx.) }\end{array}$ \\
\hline 0.6 & 11.0 & 11.0 & 11.0 & $\mathrm{~S}$ & 0 & 11.0 \\
\hline 0.8 & 7.18 & 7.18 & 7.18 & $\mathrm{~S}$ & 0 & 7.18 \\
\hline 1.0 & 5.55 & 5.55 & 5.54 & $\mathrm{~S}$ & 0 & 5.55 \\
\hline 1.2 & 4.80 & 4.80 & 4.80 & $\mathrm{~S}$ & 0 & 4.80 \\
\hline 1.4 & 4.49 & 4.49 & 4.48 & $\mathrm{~S}$ & 0 & 4.49 \\
\hline 1.6 & 4.39 & 4.39 & 4.39 & $\mathrm{~S}$ & 0 & 4.40 \\
\hline 1.7 & 4.39 & 4.39 & 4.38 & $\mathrm{~S}$ & 0 & 4.39 \\
\hline 1.8 & 4.26 & 4.26 & 4.26 & A & 1 & 4.26 \\
\hline 2.0 & 3.99 & 3.99 & 3.99 & A & 1 & 3.99 \\
\hline 2.5 & 3.72 & 3.72 & 3.72 & A & 1 & 3.72 \\
\hline 3.0 & 3.62 & 3.62 & 3.63 & $\mathrm{~S}$ & 0 & 3.62 \\
\hline
\end{tabular}
the edges parallel to the loading and clamped at the ends perpendicular to the loading 
Table 4. Values of the non-dimensional buckling parameter $\mathrm{k}$ obtained for isotropic rectangular plates, clamped on all four edges and loaded longitudinally

\begin{tabular}{cccccc}
$\begin{array}{c}\text { Aspect ratio } \\
l / \mathrm{b}\end{array}$ & $\begin{array}{c}\text { VICON } \\
\text { Example 2 }\end{array}$ & $\begin{array}{c}\text { Timoshenko } \\
\text { and Gere (1961) }\end{array}$ & Mode & $\xi$ & $\begin{array}{c}\mathrm{k} \\
\text { (approx.) }\end{array}$ \\
\hline 1.0 & 8.29 & 8.28 & $\mathrm{~S}$ & 0 & 8.29 \\
2.0 & 6.47 & 6.48 & $\mathrm{~S}$ & 0 & 6.47 \\
3.0 & 6.05 & 6.06 & $\mathrm{~A}$ & 1 & 6.06
\end{tabular}

Table 5. Values of the non-dimensional buckling parameter $k$ obtained for isotropic rectangular plates, clamped on all four edges and loaded in shear

\begin{tabular}{ccccc}
$\begin{array}{c}\text { Aspect ratio } \\
l / \mathrm{b}\end{array}$ & $\begin{array}{c}\text { VICON } \\
\text { Example 3 }\end{array}$ & $\begin{array}{c}\text { Timoshenko } \\
\text { and Gere (1961) }\end{array}$ & $\xi$ & $\begin{array}{c}\mathrm{k} \\
\text { (approx.) }\end{array}$ \\
\hline 1.0 & 12.0 & 12.1 & 1 & 12.2 \\
2.0 & 8.4 & 8.5 & 0 & 8.5
\end{tabular}

Table 6. Values of the non-dimensional frequency parameter $f$ for rectangular isotropic plates, simply supported along their longitudinal edges and clamped on their transverse ends

\begin{tabular}{|c|c|c|c|c|c|c|c|c|c|c|}
\hline $\begin{array}{c}\text { Aspect ratio } \\
l / \mathrm{b} \\
\end{array}$ & $\begin{array}{c}\text { Frequency } \\
\text { no. }\end{array}$ & $\begin{array}{c}\text { VICON } \\
\text { Example } 4 \\
\end{array}$ & $\begin{array}{l}\text { VIPASA } \\
\text { Example 4* }\end{array}$ & $\begin{array}{l}\text { Mead et al. } \\
(1988)\end{array}$ & $\begin{array}{c}\text { Yuan and } \\
\text { Dickinson (1995) }\end{array}$ & $\begin{array}{l}\text { Leissa } \\
(1969) \\
\end{array}$ & $\begin{array}{c}\text { Liew et al. } \\
(1990)\end{array}$ & Mode & $\xi$ & $\begin{array}{c}\mathrm{f} \\
\text { (approx.) } \\
\end{array}$ \\
\hline 1.0 & 1 & 28.951 & 28.951 & 28.951 & 28.951 & 28.946 & 28.95 & $\mathrm{~S}$ & 0 & 28.980 \\
\hline 1.0 & 2 & 54.743 & 54.743 & 54.878 & 54.743 & 54.743 & 54.88 & $\mathrm{~S}$ & 0 & 54.799 \\
\hline 1.0 & 3 & 69.327 & 69.327 & 70.185 & 69.327 & 69.320 & 69.34 & A & 1 & 69.449 \\
\hline 0.5 & 1 & 23.816 & 23.816 & 23.816 & 23.816 & 23.814 & - & $\mathrm{S}$ & 0 & 23.825 \\
\hline 0.5 & 2 & 28.951 & 28.951 & 28.970 & 28.951 & 28.962 & - & $\mathrm{S}$ & 0 & 28.963 \\
\hline 0.5 & 3 & 39.089 & 39.089 & 39.724 & 39.093 & 39.047 & - & $\mathrm{S}$ & 0 & 39.105 \\
\hline
\end{tabular}

Table 7. Values of the non-dimensional frequency parameter $f$ for rectangular isotropic plates clamped on all four edges

\begin{tabular}{cccccccccc}
$\begin{array}{c}\text { Aspect ratio } \\
l / \mathrm{b}\end{array}$ & $\begin{array}{c}\text { Frequency } \\
\text { no. }\end{array}$ & $\begin{array}{c}\text { VICON } \\
\text { Example 5 }\end{array}$ & $\begin{array}{c}\text { Mead et al. } \\
(1988)\end{array}$ & $\begin{array}{c}\text { Yuan and } \\
\text { Dickinson (1995) }\end{array}$ & $\begin{array}{c}\text { Leissa } \\
(1969)\end{array}$ & $\begin{array}{c}\text { Liew et al. } \\
(1990)\end{array}$ & Mode & $\xi \begin{array}{c}\mathrm{f} \\
\text { (approx.) }\end{array}$ \\
\hline 1.0 & 1 & 35.985 & 35.990 & 35.986 & 35.980 & 35.99 & $\mathrm{~S}$ & 0 & 36.013 \\
1.0 & 3 & 73.394 & 74.184 & 73.395 & 73.394 & 73.41 & $\mathrm{~S}$ & 0 & 73.447 \\
0.5 & 1 & 24.578 & 24.581 & 24.578 & 24.577 & - & $\mathrm{S}$ & 0 & 24.587 \\
0.5 & 2 & 31.826 & 31.867 & 31.827 & 31.826 & - & $\mathrm{S}$ & 0 & 31.838 \\
0.5 & 3 & 44.770 & 45.631 & 44.808 & 44.769 & - & $\mathrm{S}$ & 0 & 44.784
\end{tabular}

Table 8. Critical buckling stresses (( (in MNm-2) obtained for the isotropic T-stiffened panel of Figure 5, simply supported on the longitudinal edges and clamped on the transverse ends

\begin{tabular}{cccccccc} 
Example & Loading & VICON & Mode & $\xi$ & ABAQUS & $\begin{array}{c}\sigma^{\prime} \\
\text { (approx.) }\end{array}$ \\
\hline 6 & Lase 6 & & & & & 241.5 \\
7 & Shear & 143.0 & -1 & 147.4 & 145.3 & 235.5 &
\end{tabular}


were modelled exactly.

Example 3 covers shear loaded plates and although shear loads are not accounted for by the arguments from symmetry in Section 3 because the loading is not symmetric about $\mathrm{x}=l / 2$, applying $\mathrm{w}=0$ and $\partial \mathrm{w} / \partial \mathrm{x}=0$ constraints at every node enables the accurate results listed in Table 5 to be found by the graphical convergence techniques mentioned above. However care must be taken in extrapolating to a limiting value of $\mathrm{k}$ as $1 / \mathrm{q}^{2} \rightarrow 0$, due to discretisation effects when the spacing of the point supports exceeds the smallest $\lambda_{\mathrm{m}}$ used.

Also included in Tables 3-7 are the $\xi$ value and (except for the shear loaded examples of Table 5) the symmetry of the mode as defined in Section 3.3. It is seen that, as predicted by the theory of Section $3, \mathrm{~S}$ modes are found with $\xi=0$ and A modes with $\xi=1$. The last column of each Table lists the approximate values of $k$ or $f$ obtained using the simple procedure described in the last sentence of Section 3.7 when fifteen point supports were used to model the clamped end, with $\mathrm{q}=5$. These values show that clamped end results can be found very quickly from a single run, since in almost all cases they match the VICON results obtained accurately by extrapolation.

Examples 6 and 7 are for the isotropic T-stiffened panel of Figure 5, previously used by Watson et al., (1998), for which $\mathrm{E}=70.0 \mathrm{GNm}-2$ and $(=0.33$, and $l=1.98 \mathrm{~m}$. The skin thickness was $5.06 \mathrm{~mm}$, the flange thickness $3.1 \mathrm{~mm}$ and the web thickness $2.53 \mathrm{~mm}$. The critical longitudinal and shear buckling stresses were found, both to high accuracy by extrapolation, and also approximately using the simple procedure, with sixteen point supports located at (a) the top, (b) the bottom of the web and (c) the two edges of the flange of each stiffener, with $\mathrm{q}=5$. At the point supports, the following were constrained to be zero: (a) $\mathrm{u}, \mathrm{v}$ and $\partial \mathrm{v} / \partial \mathrm{x}$; (b), (c) $\mathrm{u}, \mathrm{w}$ and $\partial \mathrm{w} / \partial \mathrm{x}$. The results of Table 8 show that the high accuracy VICONOPT results are within $2 \%$ and $3 \%$ of the ABAQUS results, for the longitudinally and shear loaded panels, respectively. The accuracy of the approximate results again demonstrates that clamped end results can be obtained efficiently.

\section{CONCLUSIONS}

An existing method for the buckling and natural vibration analysis of panels has been extended to model panels with clamped ends more rigorously than hitherto possible. The numerical results show that the critical buckling stresses and natural frequencies obtained with a small number of point supports and a small number of half-wavelengths of response are comparable to accurate results obtained using graphical techniques and extrapolation. Arguments from symmetry show that consideration can be restricted to modes that repeat over one $(\xi=0)$ or two $(\xi=1)$ longitudinal bays of a conceptual infinitely long panel with support conditions repeating at longitudinal intervals of the true panel length 1 .

\section{ACKNOWLEDGEMENTS}

The first author gratefully acknowledges financial support from the Engineering and Physical Sciences Research Council and BAE Systems, Airbus UK Ltd.

\section{REFERENCES}

Anderson, M. S., Williams, F. W. and Wright, C. J. (1983) "Buckling and vibration of any prismatic assembly of shear and compression loaded anisotropic plates with an arbitrary supporting structure", International Journal of Mechanical Sciences, Vol. 25, No. 8, pp. 585-596.

Butler, R. and Williams, F. W. (1992) "Optimum design using VICONOPT, a buckling and strength constraint program for prismatic assemblies of anisotropic plates", Computers and Structures, Vol. 43, No. 4, pp. 699-708.

Hibbitt, Karlsson, and Sorensen, Inc. (1997) ABAQUS/Standard User's Manual, Version 5.7, Pawtucket, RI.

Ingber, M.S., Pate, A.L. and Salazar, J.M. (1992) "Vibration of a clamped plate with concentrated mass and spring attachments", Journal of Sound and Vibration, Vol. 153, No. 1, pp. 143-166.

Leissa, A.W. (1969) Vibrations of Plates, NASA SP-160.

Liew, K.M. and Lam, K.Y. (1990) "Application of two-dimensional orthogonal plate function to flexural vibration of skew plates",

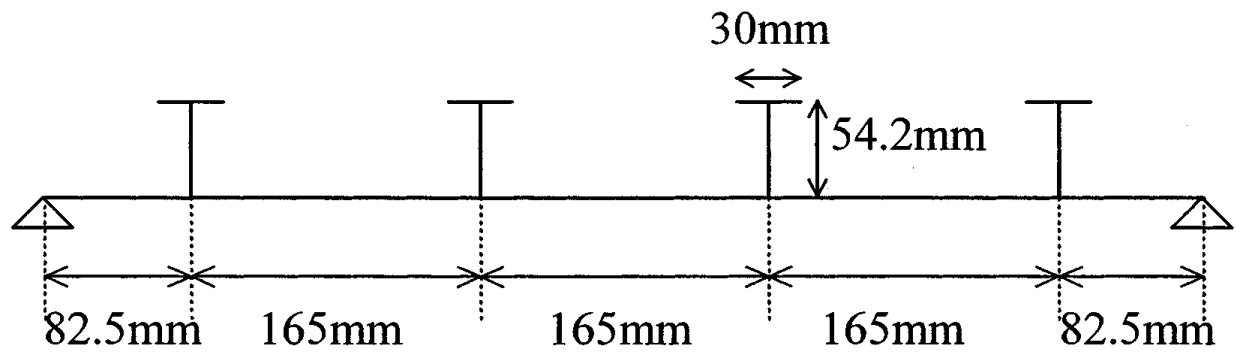

Figure 5. Cross-section of the T-stiffened panel of examples 6 and 7, simply supported along its longitudinal edges and clamped on its transverse ends. The dimensions are shown from the centre lines of plates. 
Journal of Sound and Vibration, Vol. 139, No. 2, pp. 241-252.

Liew, K.M, Lam, K.Y. and Chow, S.T. (1990) "Free vibration analysis of rectangular plates using orthogonal plate function", Computers and Structures, Vol. 34, No. 1, pp. 79-85.

Liew, K.M. and Wang, C.M. (1992) "Elastic buckling of rectangular plates with curved internal supports", Journal of Structural Engineering, ASCE, Vol. 118, No. 6, pp. 1480-1493.

Liew, K.M. and Wang, C.M. (1995) "Elastic buckling of regular polygonal plates”, Thin-Walled Structures, Vol. 21, No. 2, pp. $163-173$

Lillico, M., Butler, R., Hunt, G.W., Watson, A., Kennedy, D. and Williams, F.W. (2000) "Optimum Design and Testing of a PostBuckled Stiffened Panel", Proceedings of 41st AIAA/ASME/ ASCE/AHS/ASC Structures, Structural Dynamics, and Materials Conference, Atlanta, GA, U.S.A. Paper No. AIAA-2000-1659.

Mead, D.J., Zhu, D.C. and Bardell, N.S. (1988) "Free vibration of an orthogonally stiffened flat plate", Journal of Sound and Vibration, Vol. 127, No. 1, pp. 19-48.

Timoshenko, S.P. and Gere, J.M. (1961) Theory of Elastic Stability, 2nd edn., McGraw-Hill, New York, pp. 385-387.
Wang, C.M., Kitipornchai, S. and Liew, K.M. (1993) "Research on elastic buckling of columns, beams and plates: focussing on formulas and design charts", Journal of Constructional Steel Research, Vol. 26, Nos. 2-3, pp. 211-230.

Wang, C.M., Wang, L. and Liew, K.M. (1994) "Vibration and buckling of super elliptical plates", Journal of Sound and Vibration, Vol. 171, No. 3, pp. 301-314.

Watson, A., Williams, F.W. and Kennedy, D. (1998) "Buckling load reduction for stiffened panels due to cutouts in ribs", AIAA Journal, Vol. 36, No. 2, pp 264-266.

Wittrick, W. H. and Williams, F. W. (1974) "Buckling and vibration of anisotropic or isotropic plate assemblies under combined loadings", International Journal of Mechanical Sciences, Vol. 16, No. 4, pp. 209-239.

Young, W.C. (1989) Roark's Formulas for Stress and Strain, 6th edn., McGraw-Hill, New York, pp. 683-693.

Yuan, J. and Dickinson, S.M. (1995) "On the determination of phase constants for the study of the free vibration of periodic structures", Journal of Sound and Vibration, Vol. 179, No. 3, pp. $369-383$.

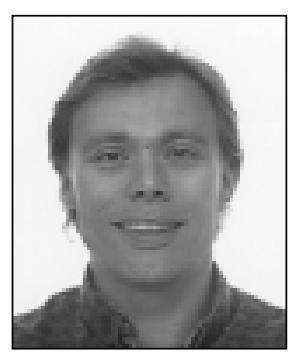

Andrew Watson graduated from Cardiff University in 1993 and then went on to obtain his $\mathrm{PhD}$ in prismatic thinwalled structures in 1998. Since then he has continued to work closely with Professor Fred W. Williams investigating the advanced postbuckling of aerospace panels jointly with the University of Bath and Airbus UK. More recently he has been looking for inter-disciplinary applications of the Wittrick-Williams algorithm.

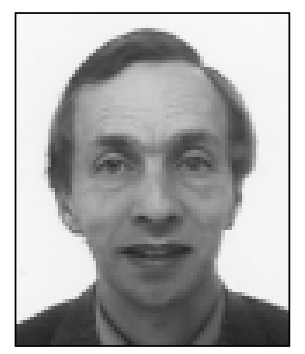

David Kennedy graduated from the University of Cambridge in 1978 and obtained a PhD from the Cardiff University in 1994. Since 1983, with support from NASA, BAE Systems and Airbus UK, he has co-ordinated the development of the space frame analysis software BUNVIS-RG and the panel analysis and optimum design software VICONOPT at Cardiff University. where he is a Senior Lecturer. Dr Kennedy has held Research Council grants on parallel computing, aerospace panel optimisation, local post-buckling and mode finding, and has assisted in the development of research agreements with leading Chinese universities. He is the author of 75 publications.

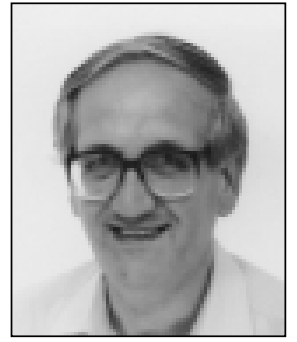

Fred W. Williams is a Chair Professor in the Department of Building and Construction at the City University of Hong Kong. He has MA and ScD degrees from Cambridge University, a PhD from Bristol University and is a Fellow of the Royal Academy of Engineering. His main research areas include transcendental eigenvalue problems (where he co-invented the Wittrick-Williams algorithm) and the buckling and vibration of structures, including many related areas of numerical analysis. He has well over 200 papers in refereed journals.

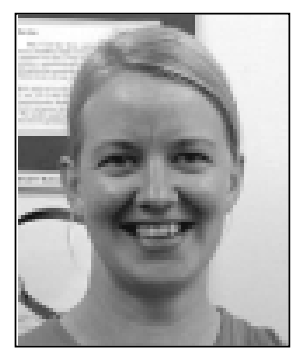

Carol A. Featherston is a lecturer in the School of Mechanical Engineering at Cardiff University and is a chartered engineer with the Institution of Mechanical Engineers. Her research interests include buckling and instability (using experimental. finite element analysis and theoretical analysis techniques) and multi-level optimisation. Her industrial experience includes work in the aeronautical, process plant maintenance and pressure vessel design engineering industries. 